Portland State University

PDXScholar

\title{
Electric Vehicle Charging Infrastructure Community Needs Assessment
}

\author{
Robert Parker \\ University of Oregon \\ Juli Brode \\ University of Oregon \\ John Rowell \\ University of Oregon
}

Follow this and additional works at: https://pdxscholar.library.pdx.edu/trec_reports

Part of the Transportation Commons, Urban Studies Commons, and the Urban Studies and Planning Commons

Let us know how access to this document benefits you.

\section{Recommended Citation}

Parker, Robert, Juli Brode and John Rowell. Electric Vehicle Charging Infrastructure Community Needs Assessment. OTREC-ED-11-02. Portland, OR: Transportation Research and Education Center (TREC), 2012. https://doi.org/10.15760/trec.62

This Report is brought to you for free and open access. It has been accepted for inclusion in TREC Final Reports by an authorized administrator of PDXScholar. Please contact us if we can make this document more accessible: pdxscholar@pdx.edu. 


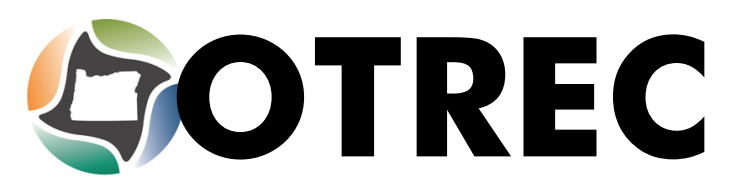

\title{
FINAL REPORT
}

\section{Electric Vehicle Charging Infrastructure Community Needs Assessment}

\author{
OTREC-ED-1 1-02 \\ March 2012
}





\title{
ELECTRIC VEHICLE CHARGING INFRASTRUCTURE COMMUNITY NEEDS ASSESSMENT
}

\author{
Final Report \\ OTREC-ED-11-02 \\ by \\ Robert Parker, AICP \\ Juli Brode, \\ University of Oregon
}

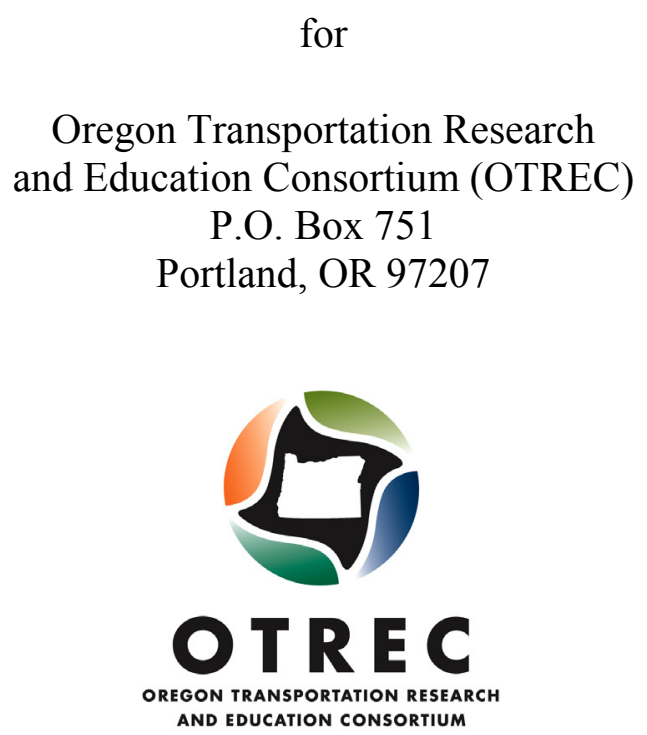

March 2012 



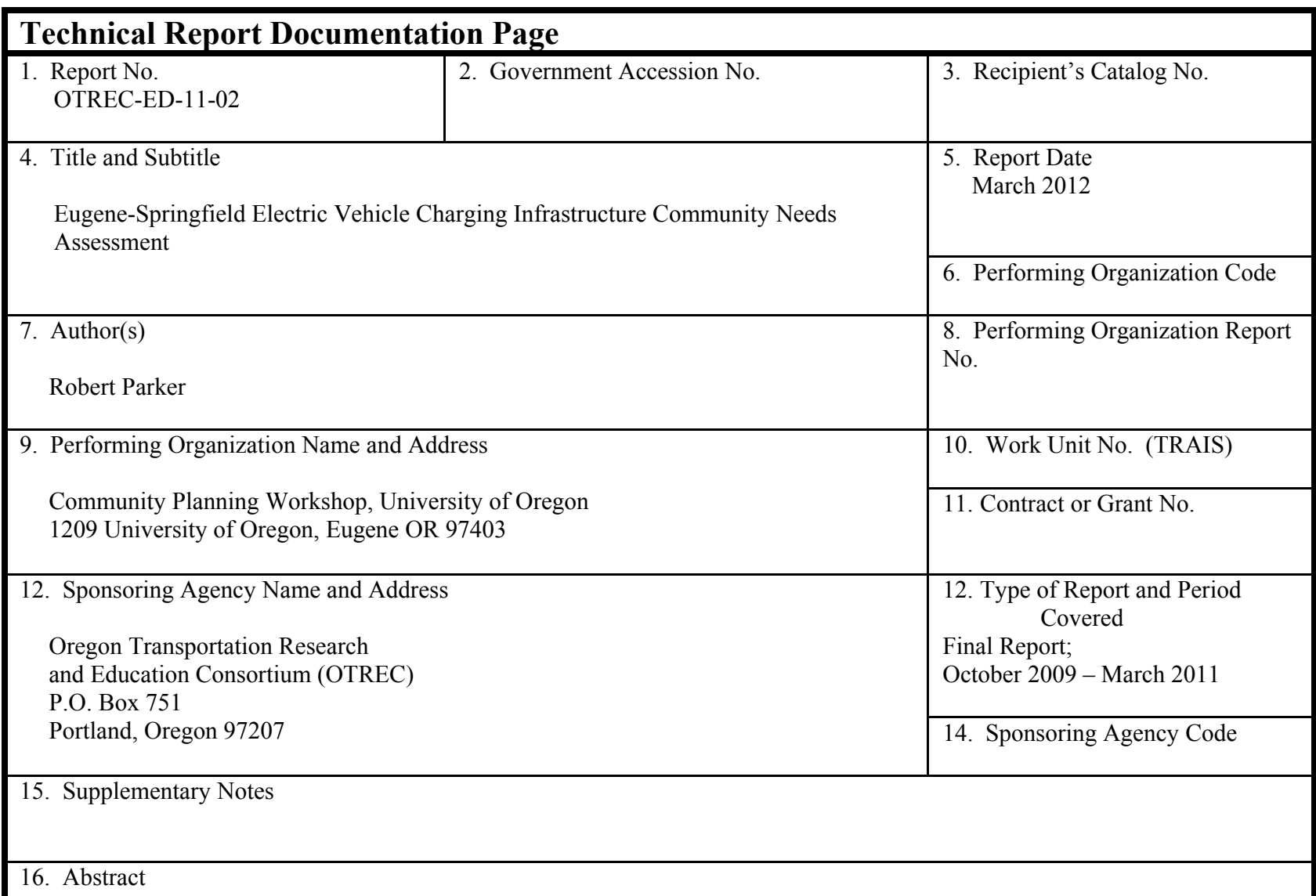

Dependence on fossil fuels, climate change, and degraded air quality are forcing the auto industry and consumers to seek alternative solutions to the current transportation system. Significant technical breakthroughs are allowing automakers to develop electric vehicles (EVs) that transcend some of the key barriers that limited them historically. Plug in electric vehicles entered the Oregon marketplace in early 2011. A range of reports suggest the demand for EVs will grow rapidly once affordable highway speed vehicles become available.

ODOT identified the lack of a reliable network of electric vehicle service equipment (e.g., charging stations) that increases the range of these vehicles as the biggest barrier to widespread adoption of EV technology. The demand for charging stations is expected to grow quickly as ODOT forecasts that EVs may account up to $20 \%$ of the new vehicles sold on Oregon within a decade.

This project included the following elements: (1) a literature review on EV technology and development strategies; (2) a local demand assessment; (3) assessment of power load implications for local utilities based on local demand and different charging station scenarios; (4) charging station siting implications, including required infrastructure; (5) potential locations for charging infrastructure in Eugene-Springfield metro area; (6) development of materials and outreach strategies to raise public awareness of EVs; and (7) product designs for EV charging stations.

This project directly supports OTREC's objectives for educational proposals. CPW's transportation focused service learning class in collaboration with Design Bridge (1) increased the transportation element of an existing class, and (2) provided opportunities for students to integrate transportation into architectural design, thereby promoting learning across disciplines in the transportation field.
17. Key Words
service learning, electric vehicles, community transportation planning
18. Distribution Statement
No restrictions. Copies available from OTREC: www.otrec.us

\begin{tabular}{|c|c|c|c|}
\hline $\begin{array}{l}\text { 19. Security Classification (of this } \\
\text { report) }\end{array}$ & $\begin{array}{l}\text { 20. Security Classification (of this } \\
\text { page) }\end{array}$ & $\begin{array}{l}\text { 21. No. of Pages } \\
24\end{array}$ & 22. Price \\
\hline
\end{tabular}




\section{ACKNOWLEDGEMENTS}

The Community Planning Workshop (CPW) would like to thank the Oregon Transportation Research and Education Consortium (OTREC) for funding this project, and the students who eagerly learned about transportation planning and worked hard to create the project deliverables. Finally, CPW would like to thank Eugene Water and Electric Board and the City of Eugene for embracing the service learning model and working collaboratively with CPW students. This project is an outstanding example of leveraging federal money, local dollars and university resources to create a true community-based project that can serve as a model for other communities and universities.

\section{DISCLAIMER}

The contents of this report reflect the views of the authors, who are solely responsible for the facts and the accuracy of the material and information presented herein. This document is disseminated under the sponsorship of the U.S. Department of Transportation University Transportation Centers Program in the interest of information exchange. The U.S. Government assumes no liability for the contents or use thereof. The contents do not necessarily reflect the official views of the U.S. Government. This report does not constitute a standard, specification, or regulation. 


\section{TABLE OF CONTENTS}

EXECUTIVE SUMMARY ...............................................................................

1.0 BACKGROUND AND OBJECTIVES......................................................3

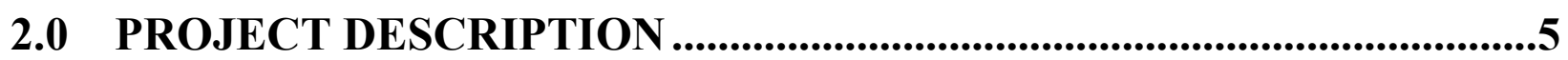

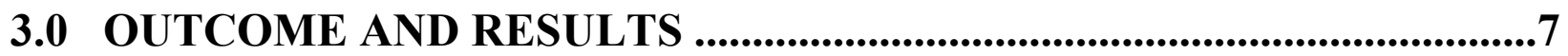

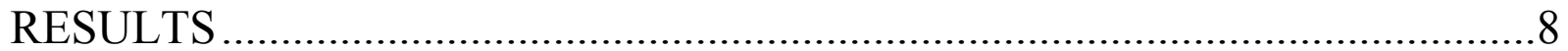

4.0 FURTHER ACTIVITIES ..............................................................................11

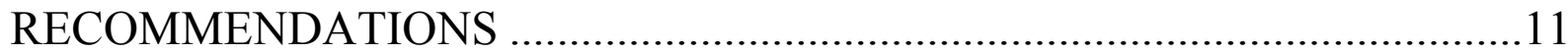

ACTION STEPS TO TAKE NOW (YEARS 1 - 2) …....................................12

LONGER-TERM ACTIONS (YEARS 3 TO 6) ..........................................13

1.1.1 ONGOING ACTIONS (YEARS 7+) ...............................................13

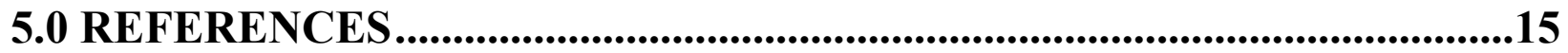




\section{EXECUTIVE SUMMARY}

This OTREC education project links experiential education with local transportation planning through a collaborative partnership between the University of Oregon, Eugene Water and Electric Board (EWEB) and the City of Eugene. The Community Planning Workshop (CPW) is an experiential learning program affiliated with the Department of Planning, Public Policy and Management at the University of Oregon. Through this service learning program, graduate students learn professional planning skills while assisting communities in actual planning and policy projects.

The CPW student team completed eight deliverables for this project: (1) a literature review on electric vehicle (EV) technology and development strategies; (2) a local demand assessment; (3) measurable power load implications for utilities based on the local demand assessment and different charging station scenarios; (4) an assessment of charging station siting implications, including required infrastructure, as well as siting opportunities and challenges, such as local developmental codes and safety issues; (5) a map of potential locations for charging infrastructure in the metropolitan area; (6) an analysis of pricing implications, potential pricing structures, and regulatory issues for fleet, residential and convenience charging sites; (7) a list of potential sites for EV charging stations and design at the point-of-delivery; and (8) the development of materials and outreach strategies to raise public awareness of EVs. In addition to the deliverables, this project facilitated the development of a rich, cross-disciplinary, experiential learning opportunity that could be replicated at other universities.

This project involved a variety of people: Approximately 30 stakeholders, including city staff, EWEB staff, policymakers, community leaders and transportation experts, provided input on the development of the deliverables. Six university graduate students conducted background research, a survey and interviews, and wrote the deliverables.

Additionally, the project engaged four students in the UO Product Design and designBridge programs to develop prototype charging station designs. The Product Design students worked under the supervision of faculty and professionals from Nike and other corporations.

Each of the project deliverables furthers OTREC priorities and goals for education projects, and will build support for innovative methods of teaching in the field of transportation study. 


\subsection{BACKGROUND AND OBJECTIVES}

Transportation planners, the auto industry and consumers are seeking alternatives to the internal combustion engine. Electric vehicles (EVs) are an increasingly feasible alternative and may soon be widely available to individual consumers and businesses. EVs, however, represent a nascent technology. Their implications for cities and transportation systems have yet to be fully understood.

The Pacific Northwest, with its abundant wind energy and hydropower, is an ideal location for the large-scale deployment of electric transport. In 2009, Oregon and Washington were identified as two of five sites for a federally funded EV and charging infrastructure demonstration project. Known as The EV Project, it is a partnership between ECOtality (formerly known as eTec) and Nissan North America. Funded by a $\$ 99.8$ million grant from the U.S. Department of Energy, the project includes the large-scale deployment of Nissan's new zero-emissions LEAF, as well as the deployment and evaluation of new EV charging infrastructure.

The Oregon Department of Transportation (ODOT) forecasts strong growth in the demand for electric vehicles, and estimates that they may account for up to 20 percent of new vehicles sold in the state within a decade (State of Oregon, 2010). In the same study, however, ODOT also identified the lack of a reliable network of charging facilities as the most significant barrier to the widespread adoption of EVs, suggesting that careful attention be given to infrastructure development.

In the Eugene-Springfield metropolitan area, the focus of this study, local governments are keenly aware of the potential environmental and economic benefits of electric vehicles, and have expressed support for the establishment of a charging infrastructure. In particular, the City of Eugene has incorporated the provision of public EV charging stations into local sustainability goals. Specifically, the Eugene City Council adopted goals to reduce greenhouse gas emissions by 80 percent by 2050 and fossil fuel consumption by 50 percent by 2020 .

The steps for achieving these goals have yet to be fully defined. Provision of public EV charging stations, however, was included in the City's draft climate action plan. Few precedents yet exist to guide cities in the installation of EV charging infrastructure, a technology still in its infancy. The need for a better understanding of EVs is particularly urgent with the arrival of EVs in Eugene-Springfield. 


\subsection{PROJECT DESCRIPTION}

This project was funded by the Oregon Transportation Research and Education Consortium (OTREC) as part of a broader initiative in support of EV research. In 2009, OTREC funded EVrelated research at four participating campuses around the state (Portland State University, University of Oregon, Oregon State University, Oregon Institute of Technology). The purpose of this project was to assess the implications of EVs for the Eugene-Springfield metropolitan area. The project included the following elements:

- Preparation of a literature review focused on EV technology and strategies for its development.

- Assessment of local demand for EVs.

- Identification of power load implications for utilities based on the local demand assessment.

- Identification of siting implications, opportunities, and challenges, such as local developmental codes and safety issues.

- Mapping potential locations for charging infrastructure in the metropolitan area.

- Development of prototypical charging station designs.

- Development of materials and outreach strategies to raise public awareness of EVs.

In preparing this report, CPW drew on existing EV research, and conducted an online survey to gauge local EV demand and preferences for charging station locations. We combined existing research with community input to ensure that our conclusions and recommendations reflect the unique characteristics of the Eugene-Springfield community. 


\subsection{OUTCOME AND RESULTS}

This project resulted in the following six deliverables:

- EV Community Needs Assessment: This report examines the history and state of technology of EVs and Electric Vehicle Service Equipment (EVSE); an analysis of current market trends; implications for the local utility power load; and recommendations for future installations in Eugene and Springfield.

- EV Fact Sheet: This document acts as a community education resource. Frequently asked questions pertaining to EVs are outlined and explained in layperson's terms.

- Map of Potential Locations for EVSE Units: Using information gathered from the CPW survey and feedback from the EV Steering Committee, the CPW research team mapped potential locations for EVSE units.

- Eugene/Springfield EVSE Permitting Guide: CPW designed a brochure to assist community members in the installation and necessary permitting of EVSE units in their homes.

- Get Plugged In! Electric Vehicle Open House: CPW created a trade show-style event held at the Wheeler Pavilion at the Lane County Fairgrounds. This event featured a number of vendors and EV enthusiasts, as well as an expert's panel and a keynote speech by George Beard of Portland State University.

- EV Charging Infrastructure Brochure: designBridge and Product Design produced a brochure that summarizes key EV information and shows prototype charging station designs.

In addition to the six deliverables, this project also contributed to the following, less quantifiable achievements:

The development of a rich, cross-disciplinary, experiential learning opportunity Twenty-one graduate students and two undergraduate students participated in the CPW class between January and June 2010. Additionally, four students participated in the Product Design studio. Not all of these students worked on developing the deliverables mentioned above; however, they benefited from the enhanced curriculum.

\section{Building collaborations between academia, public-sector organizations and private-sector experts \\ This project required close and well-managed interactions between the University of Oregon, public-sector organizations (Cities of Eugene and Springfield, EWEB, Springfield Utility Board, and Lane Community College) and private-sector experts (Good Company, ECOtality, and Solarc). This collaboration, lead by CPW, gave an important perspective to the project and}


provided students with the opportunity to interact with seasoned professionals. CPW can be considered an "unbiased" party that has no motivation to promote a positive and/or negative image of EVs. This allowed CPW to facilitate the interactions between public-sector organizations, community groups, private-sector professionals and other interested parties. It also gave many of the participants comfort in believing that their perceptions would be recorded correctly and presented, unbiased, to their co-sponsors.

\section{RESULTS}

The goal of this project was to evaluate the implications of incorporating EV use and infrastructure in the Eugene-Springfield metropolitan area. The framework builds from local input and data analysis. To develop it, we conducted interviews with local experts, analyzed publicly available market data for the region, and conducted a web-based poll of area residents. Given this context, our key conclusions follow:

- Local interest in EVs appears high. Based on their expressed intent to purchase an EV, survey respondents expressed a surprisingly high level of confidence with EV technology. A large percentage of respondents (41\%) also plan to buy an EV or are considering buying one. These facts, taken together, may suggest that there is a pent-up demand for EVs.

- EV technology is not a serious barrier to early EV adoption. On a case-by-case basis most homes can be upgraded to include charging equipment. Barriers related to insufficient power, or local infrastructure inadequacies, will only occur (if at all) at a later date.

- Some perceived barriers (safety, range anxiety, etc.) may keep many potential EV buyers on the sidelines for years to come. However, there is some evidence that these concerns are rapidly diminishing. Moreover, external factors such as gasoline prices and federal greenhouse gas legislation could accelerate EV adoption.

- Local adoption will probably occur faster than national rates. We expect that Eugene will experience higher demand for EVs per capita than most mid-sized cities in the U.S. We estimate that the cumulative demand for EVs in the Eugene-Springfield area will be roughly 9,000 (low estimate) to 14,000 (high estimate) vehicles by the year 2020. We further expect that EV sales will mirror early hybrid sales, and that in the short term (one to three years) demand for EVs will exceed supply.

- It is not clear how important publicly accessible EVSE is in the long term. The answer to this question depends on factors on which we have little reliable data. Studies suggest that the presence of highly visible EVSE in public locations is important to curb concerns about range anxiety. The fact is that most commuters in our region drive less than 40 miles per day - a distance that is well within the range of contemporary EVs. The longer-term need for publicly accessible EVSE is less clear; it depends on a variety of factors that include technological advances that increase the range of EVs and how those factors affect travel behavior. 
- Evidence suggests a preference for EVSE in high-profile locations. Respondents to the community survey expressed a preference for public charging stations in the downtown Eugene area, places of employment, and large shopping and retail centers.

A key challenge of planning for EVs is the fact that they, in their current form at least, utilize relatively new technologies that are coming to market at a time when tremendous economic and political changes are occurring in the energy and transportation sectors. In this environment the 'knowns' are subject to rapid change. The introduction of EVs into our community presents many opportunities; however, it also presents an enormous challenge - that of keeping up to date with this pace of change.

The pace of change is one issue that local governments and utilities should be concerned about. The potential exists for extremely rapid adoption of EVs, a scenario that has profound implications for local governments. Among the most important are impacts on power demand and load and the location and management of EVSE. While rapid adoption is far from certain in the U.S., the evidence suggests that EV technology is ripe and is close to reaching a critical mass. External factors such as gasoline prices and federal greenhouse gas legislation could cause quicker adoption rates.

Despite these challenges, EV technology meets multiple needs of local residents and public agencies. Its adoption complements and supports strategic economic goals of the State of Oregon as well as climate action and sustainability goals for the City of Eugene and the nation. However, four key questions emerged from our investigation as unanswered, or only partly answered:

- Do consumer concerns about EVs create a barrier to local adoption and, if so, how can they be overcome? What actions should local governments take to promote adoption?

- What should local electric utility providers do to prepare for the potential electrical load increases that will arrive with widespread EV adoption?

- Could increasing demand for EVSE-related permits become a barrier to EV adoption? What action should be taken to streamline permitting processes in anticipation of this demand?

- How should these actions be prioritized? What are the appropriate timeframes for addressing each? 


\subsection{FURTHER ACTIVITIES}

CPW developed a set of locally focused recommendations as part of the community assessment. These recommendations were targeted at Eugene, Springfield, the Eugene Water and Electric Board (EWEB), and the Springfield Utility Board (SUB) as well as other local, state and federal partners.

\section{RECOMMENDATIONS}

As noted, EV technology supports existing polices of the state and City of Eugene. It is a primary recommendation of this report that the City of Eugene, the City of Springfield, Eugene Water and Electric Board (EWEB), Springfield Utility Board (SUB), and the University of Oregon should actively promote the adoption of EV technology. This work would be facilitated by the creation of a working group of employees from each agency. The role of such a group would be to create and maintain an effective feedback loop between agencies. This should promote dialogue and alignment on the myriad issues that will arise related to the implementation of EVs.

\section{Figure S-1. Recommended Action Steps}

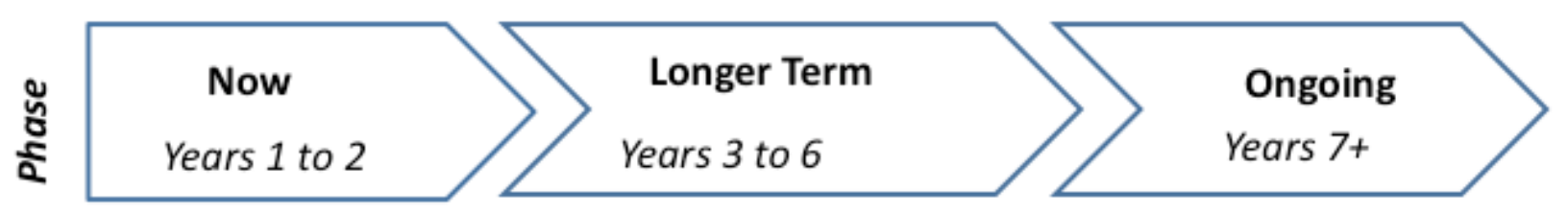

\footnotetext{
- Form EV Working Group \& - Implement fleet purchases EV Advisory Council

- Secure consumer feedback / Conduct public outreach

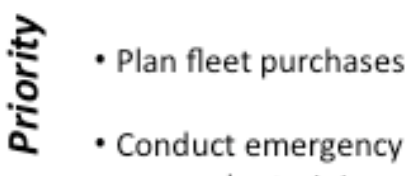
responder training

- Research smart metering and tiered pricing

- Coordinate EVSE permitting and notification procedures

- Update land use codes

- Prioritize locations for 2 nd wave of EVSES

- Place infrastructure for 2 nd wave of EVSE's / Upgrade transformer network

- Develop long term 'smart-grid' implementation strategy

- Develop "Green Street" strategy

- Implement smart metering

- Implement tiered pricing

- Determine alternate revenue sources

- Develop 'One Stop Shop' process for home EVSE permitting and installation
} 


\section{Action Steps to Take Now (Years 1- 2)}

As a guiding principle, local governments and institutions should seek to promote EVs through the visible, prominent placement of charging stations. They should also work to assure that their various efforts are efficiently coordinated and that the constituencies they represent are both informed and consulted with regard to EVSE infrastructure planning. In that light, the most urgent action steps are those which will facilitate outreach, communication, and long-term planning.

- Adopt Local Policy Statement. Local governments and utilities should adopt a policy statement in support of EV adoption and establish a formal EV Working Group comprised of employees from each agency.

- Establish an Advisory Committee. A community advisory body, similar in scope to the Bicycle and Pedestrian Advisory Council, should be formed to provide input to, and assist with, the implementation of these steps.

- Research EV User Needs. Local governments should pay attention to user needs. It will be critical to respond to the needs of early adopters.

- Develop a Community Education Strategy. The city governments and EWEB should initiate a community education campaign about these vehicles, their benefits, and their potential impact on power supply for the area.

- Consider Fleet Purchases. Local governments can demonstrate a commitment to EV technology through fleet purchases. Fleet purchases help mainstream new technology in the eyes of the public and, therefore, are key to public education and acceptance.

- Train First Responders. Incorporate EV manufacturers' recommendations into emergency responder procedural documentation. Provide training and certification for all responders.

- Follow EVSE Business Models. Utilities will need to come to terms with the long-range policy decisions that will determine future EVSE business models. Questions about pricing for EV charging and cost recovery for infrastructure upgrades needed to support EVSE must be addressed, as must future maintenance responsibilities for installed infrastructure.

- Monitor Power Loads. Our modeling suggests that an increase in overall power load demand will not affect EWEB and SUB in the first few years. This will give both utilities time to study and learn from other communities that are aggressively promoting EV technology. 


\section{Longer-Term Actions (Years 3 to 6)}

Careful long-range planning is necessary to successfully integrate electric vehicles into the regional transportation network. With this in mind, we recommend the following actions be carried out over a slightly longer time period:

- Institutionalize Fleet Purchases. Incorporate EVs into government and institutional fleet purchases. Set purchase targets for EV's in fleets by 2020 that equal or exceed the historic pace of hybrid fleet adoption.

- Review land use codes. Review and update land use codes to reflect EV parking and signage requirements. Consideration should be given to amending building codes and / or land use codes to require placement of conduits for future EVSE in new parking garages and multifamily housing developments.

- Develop a community-wide EVSE strategy. Local governments should form a working coalition to define and implement a methodology for prioritizing charging station locations once the initial DOE-funded wave of installations is complete. Consideration should be given to the possibility of a level three EVSE unit rollout.

- Conduct research on the travel behavior of EV owners. While it is conceivable that the behavior of EV owners will be a lot like those of conventional vehicle owners, the cost and range of EVs may lead to shifts in how people use EVs.

- Develop a "Green Streets" program. Such a program would create restricted travel corridors for electric vehicles, bicycles, pedestrians, and other low-impact transportation modes. A green street would make use of existing infrastructure, but would address safety concerns by creating dedicated right-of-ways for certain classes of vehicles and transportation modes.

- Develop a "one-stop shop" program. Over the next few years, the priorities of EV manufacturers, and of policymakers who wish to promote EV adoption, must be to ensure that in-home charging equipment can be easily and affordably installed by early buyers. But to satisfy this need several problems must first be overcome. Section D of the Appendix outlines a proposed "one-stop shop" program to address these issues.

\subsubsection{Ongoing Actions (Years 7+)}

Over the longer term, as EV adoption reaches critical mass, action focused on outreach, study and planning must result in the implementation of changes on a broader scale.

- Implement the planned combination of EV-enabling technologies (smart-metering/tiered pricing/consumer education).

- Develop a strategic plan for eventual supplementation of revenues lost from falling gas sales. 


\subsection{REFERENCES}

State of Oregon. (2010, May 24). Innovative Partnerships Program. Retrieved June 05, 2010, from Office of Innovative Partnerships and Alternative Funding:

http://www.oregon.gov/ODOT/HWY/OIPP/inn_ev-charging.shtml 



\section{GOTREC \\ AND EDUCATION CONSORTIUM}

P.O. Box 751

Portland, OR 97207

OTREC is dedicated to stimulating and conducting collaborative multi-disciplinary research on multi-modal surface transportation issues, educating a diverse array of current practitioners and future leaders in the transportation field, and encouraging implementation of relevant research results. 